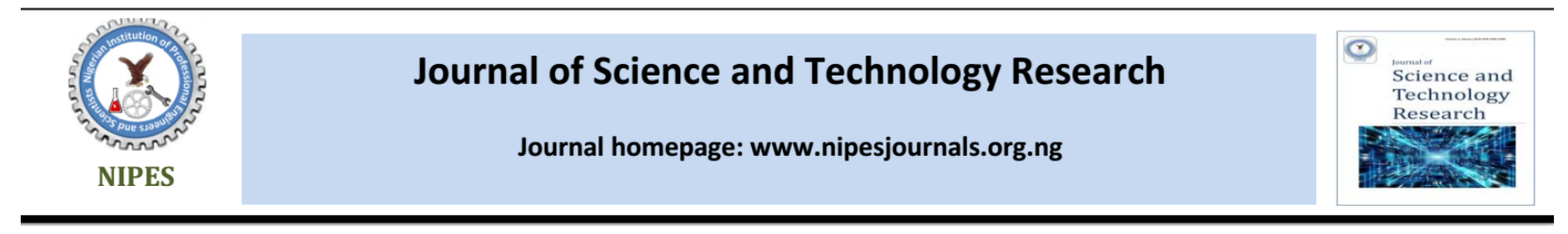

\title{
Determination of the Pressure Regimes in the Design of a Portable Faecal Slurry Evacuation System
}

\section{Sadjere, E.G. and Iloba, N.}

Department of Mechanical Engineering, University of Benin, P.M.B 1154, Benin City, Nigeria

\section{Article Info}

Received 06 August 2020

Revised 17 August 2020

Accepted 22 August 2020

Available online 31 August 2020

\section{Keywords:}

Faecal Slurry, Pressure Regime,

Evacuation System, Water-ring Pump

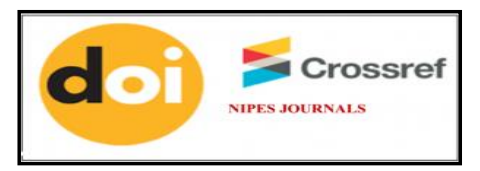

https://doi.org/10.37933/nipes/2.3.2020.32

\begin{abstract}
The evacuation of latrines and septic tanks often requires the design of portable machines that can be moved to location to pump out the faeces slurry. This paper explores the process of determining the pressure regime in the vacuum suction system used for the evacuation. These are the pressures in the vacuum chamber and pump for the suction and blow flow of the faeces slurry. The suction and blow pressures in the suction chamber were determined using Herschel-Buckley model equation for non-Newtonian fluids and the Bernoulli's energy equation while the pressure in the water-ring vacuum pump used gas flow equations. The pressures determined for the $100 l$ vacuum chamber for a $33.4 \mathrm{~mm}$ (11/4 in) pipe were suction pressure of 37,302 $\mathrm{Pa}$ vacuum and blow pressure of 187,756 $\mathrm{Pa}$ gauge. The critical pressure for the continuum gas flow in the waterring pump using a $12.5 \mathrm{~mm}(1 / 2$ ") nozzle was 68,900 Pa but has to be reduced to 37,302 $\mathrm{Pa}$ before the flow will seize
\end{abstract}

\section{Introduction}

A major environmental issue in Nigeria is the problem of the disposal of faecal wastes. This assertion is corroborated by a study of faecal sludge management in Africa - Nigeria Study Report commissioned by the Bill and Melinda Gates Foundation [1]. The study concluded that, the disposal practices in all the cities studied are not appropriate and there is need for further developing efficient disposal facilities. Many towns in Nigeria are suburban settlements where development started in earnest in the immediate post independent era. These urban dwellings started with the proliferation of shanty dwellings, squatter settlements and slums [2]. The houses built in this era were mostly "room and parlour" apartments, colloquially referred to as "face-me-I-face-you". These houses were built in unplanned narrow lanes or alleys, meandering through the settlements. The toilets were mostly deep pit latrines or bucket or pail latrines. These were legacies of the British Colonial Masters as practices of $19^{\text {th }}$ century Europe. The pail latrines were evacuated and disposed into designated areas by night-soil-men but went virtually into extinction in the late 1970s as a result of urban development and scarcity of night-soil-men due to the debasing nature of the work. Some deep-pit latrines still exist to date in these old townships though many have been replaced with water-flushed toilet systems. The new toilet systems are equipped with various sizes of septic tanks and soak away pits.

A major problem associated with the latrines or septic tanks is the evacuation of the faeces as they fill up, due to the poor access as a result of the narrow lanes or alleys. The most popular method of 
evacuating septic tanks and latrines is the use of vacuum tankers. These come in various sizes: from the very large to medium and small sizes. However, the narrow lanes and alleys make it difficult for the vacuum tankers to access the septic tanks and latrines. It is difficult for even the smallest vacuum tankers to meander through these narrow lanes to access the septic tanks; and, when the lanes could be navigated, accessing the septic tanks and latrines still poses daunting problem because, most often, they are situated at the back of houses and it takes the longest of hoses to actually get to the pit and lots of difficulty to attain suction pressure. This is why there is need to design evacuation systems that could get as close to the pit as possible and used for the evacuation of these septic tanks and latrines.

Not much has been done in Nigeria by way of suitable designs to solve this perennial problem though some designs have been developed and built in other African countries to solve similar problems. These include the Microvac, one of the smallest vacuum tankers for evacuation of pits. It has the features of the usual vacuum tanker but developed for use in rural areas with poor access [3]. That, notwithstanding, it still suffers most of the drawbacks of large vacuum tankers. Another popular design was the MAPET, developed by a Dutch NGO and deployed in Dar es Salaam in Tanzania in the early 1990s [4]. The MAPET uses a custom-built piston pump to create vacuum in a 200-L steel drum to suck up the faeces into the drum for evacuation. Some of the drawbacks were the corrosion of, and eventual implosion of the steel drum; facilities to mix the sludge into suckable slurry; and means of removing rags and other extraneous materials from the pit. There was also the Dung Beetle, developed in Ghana by J. Hvidtved Larson and mounted on two wheels and driven by a driver sitting on the tank [3]. The machine was successfully used in Ghana for many years and can access very difficult areas but still requires at least $3.3 \mathrm{~m}$ between walls and a turning radius of $3 \mathrm{~m}$, which is a limitation to its application in much smaller access road. The Vacutug [5], was another successful design which was an UN-HABITAT project. The project was funded by the British Development Fund for International Development (DFID) with the support from Irish Aid. It evolved out of the need for a low cost and fully sustainable system for emptying pit latrines in unplanned peri-urban areas and refugee camps and started way back in Botswana in 1983. The specifications of interest in this study are its size which is L $3900 \mathrm{~mm} \times \mathrm{W} 1350 \mathrm{~mm} \times \mathrm{H} 2000 \mathrm{~mm}$ and makes it easily manoeuvrable but the high capacity engine and large size of the holding tank are some of the disadvantages. The vacuum pump was a Battiono \& Pavesi Type 2000P rated vacuum 0.9 bar and rated pressure 2.0 bar. The machine, was manufactured in Bangladesh and spare parts were readily available but were expensive and have to be imported. Finally, there was always the problem that fully accessing the pits or latrines require long hoses and loss of pressure.

All these designs are based on the principle of creating vacuum in a chamber to suck up the sludge from the pit. The development of most of this equipment met with many challenges, most of which are still prevalent, particularly, in attempt to domesticate the designs and make them affordable for developing economies like Nigeria. These challenges can be summarized to include designing for the vacuum regime in the system; getting appropriate pumping system to create the required vacuum; preventing the sludge or slurry from damaging the pump components; and miniaturizing the system for evacuating smaller chambers. The design presented here is the determination of the pressure regime in a prototype small vacuum tanker of 100-L capacity that could be mounted on wheels and hand pushed to the pit or latrine.

\section{Methodology}

The design was based on the vacuum-suction principle. The system is illustrated in Figure 1. It consists of a water-ring vacuum pump connected through a separator to the sludge tank, which receives the slurry being pumped from the pit. 


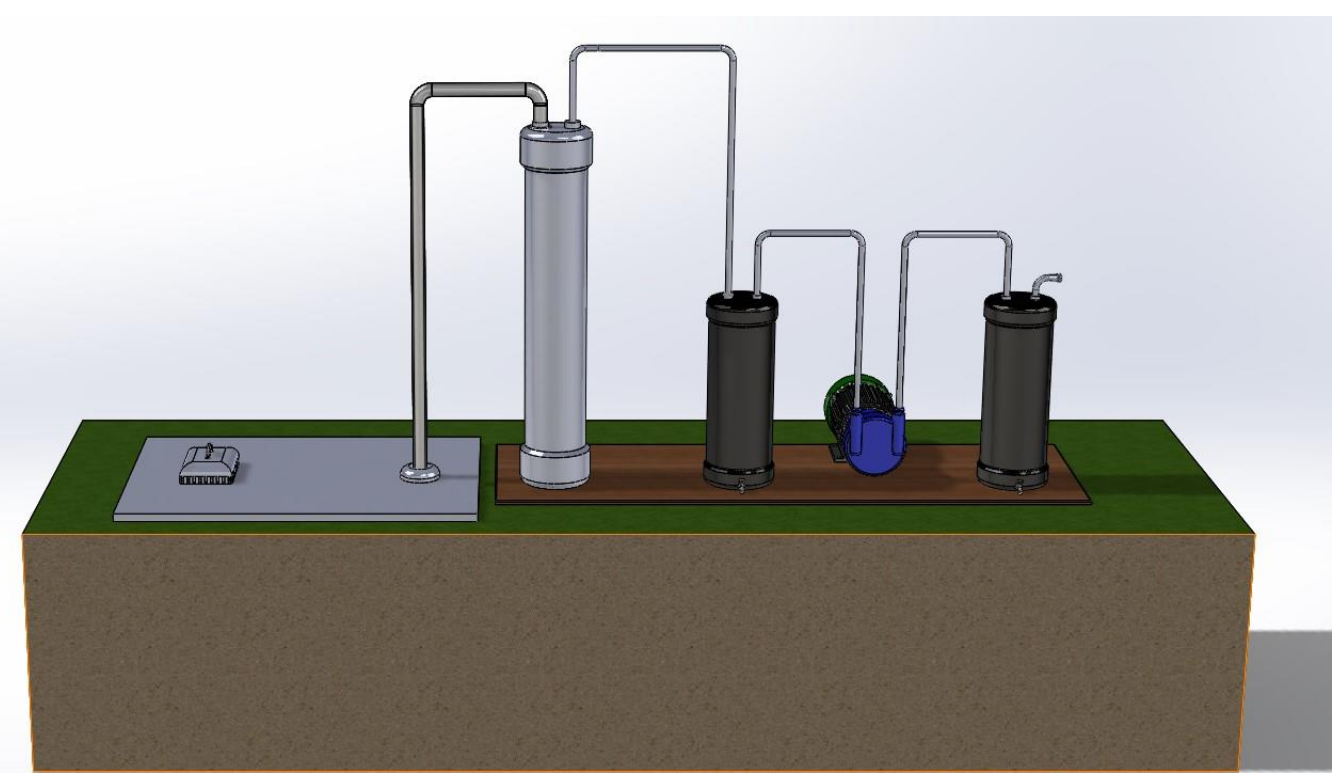

Figure 1a: Faecal Slurry Evacuation System

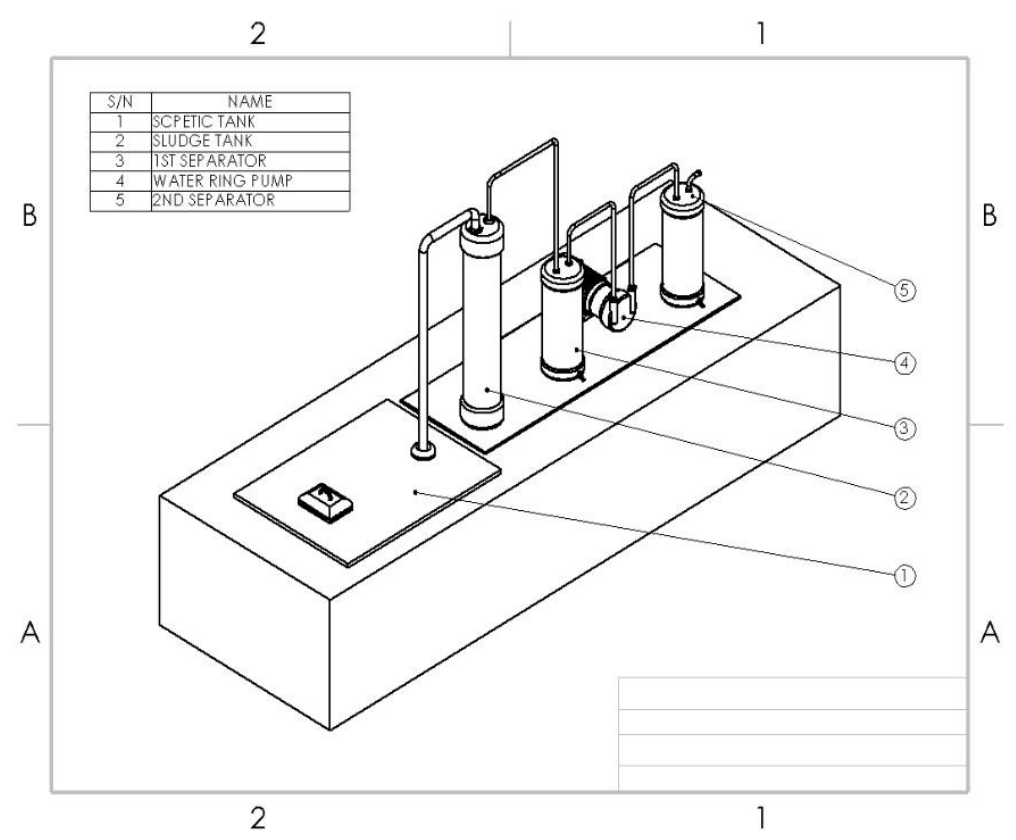

Figure 1b: Faecal Slurry Evacuation System - Annotated

Air in the sludge tank is evacuated to create a vacuum by the suction effect of the water-ring pump. The vacuum sets up the suction of the faecal slurry into the sludge tank. The air suction line from the sludge tank to the pump is equipped with a float valve in the sludge tank. The valve closes when the sludge in the tank attains a set level and prevents the suction of faecal slurry into the pump. This float valve acts as a primary protection for the pump. A second float valve is installed in the separator. The separator traps any faeces that may pass the primary valve as a result of turbulence. Such carryover slurry drops by gravity to the bottom of the separator and is removed through the drain. A second separator is attached to the pump discharge line. This is meant for the separation of water carried over from the water-ring pump. This separator is also equipped with a float valve. The 
discharge line has a Tee connection that is used for the 'blow' option. For this operation, the sludge tank is connected to the discharge line of the pump to deliver gauge pressure to push out the slurry.

\subsection{The Pressure System}

Figure 2 illustrates the design pressures of the system. The vacuum pump working at pressure $\mathrm{P}_{3}$ creates a vacuum at a pressure $\mathrm{P}_{2}$ in the sludge tank which draws up sludge from the sludge pit at a depth of $Z_{1}$ and pressure $P_{1}$. The pump can also be controlled to create positive pressure $P_{4}$ in the tank and pump the sludge into a disposal tank at a pressure $\mathrm{P}_{5}$ and elevation of $\mathrm{Z}_{3}$ above the machine. This paper is devoted to determining the various operating pressures in the system.

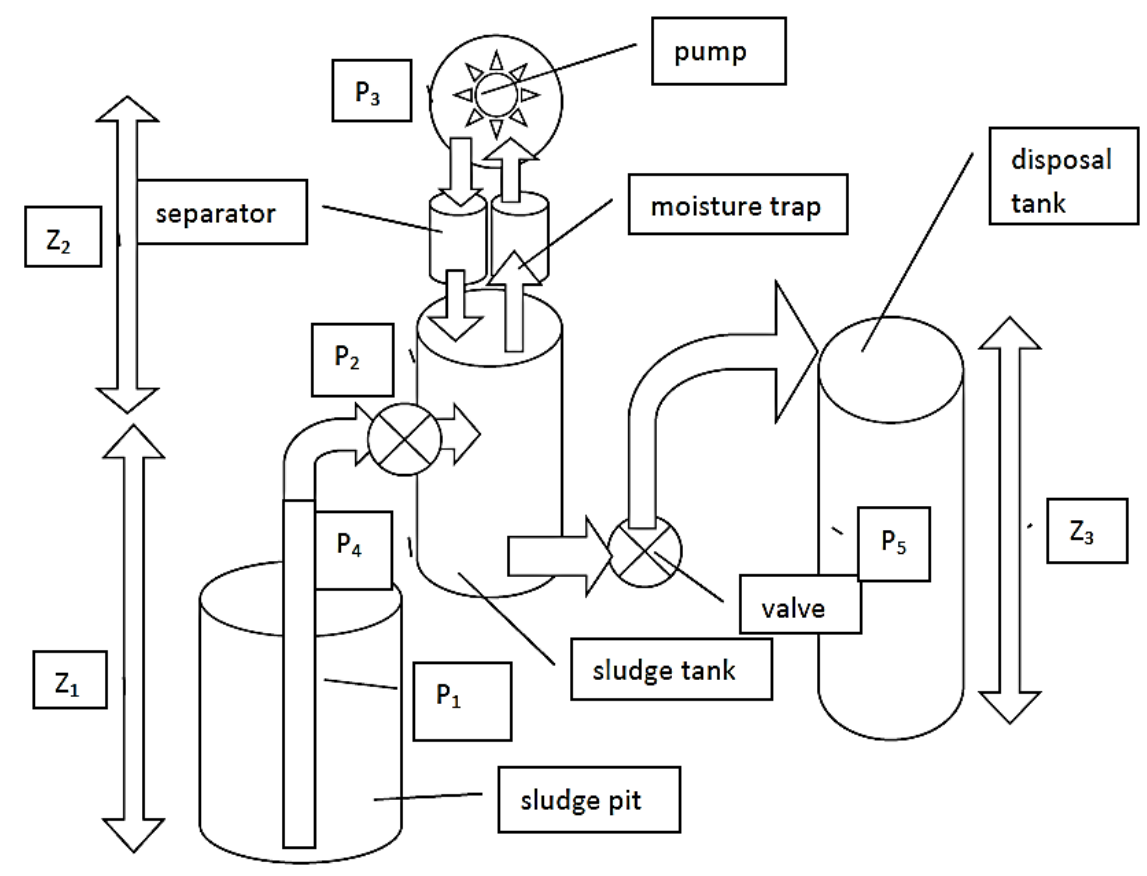

Figure 2: Schematic Diagram of the Sludge Evacuation System

\subsection{Friction Losses}

In determining the system pressures, it was first necessary to determine the friction losses as the sludge is drawn from the sludge pit into the sludge tank before applying the Bernoulli's energy equation to calculate the required pressures. The rheological parameters used for the design is for waste water (black water) described as clarified sewage sludge (Waukesha Cherry-Burrell, 2015). Waste water can be classified, based on the level of contamination contained into black water and grey water. Grey water is polluted water which has not been in contact with faecal matter while black water is sewage water which has faecal matter, bacteria and disease-causing pathogens.

\subsection{Design Specification}

The specifications used in the design are according to British standard EN12050-1 in British Standards Institution, BS EN12050-1, (2015) that specify parameters for sewage systems. The parameters include:

1. Density, $\rho=1100 \mathrm{~kg} / \mathrm{m}^{3}$

2. Flow velocity, vertical pipes: $1-3 \mathrm{~m} / \mathrm{s}$

3. Flow velocity, horizontal pipes: $0.7-2.3 \mathrm{~m} / \mathrm{s}$ 
4. $\quad$ Pipe size, diameter: $40 \mathrm{~mm}$ (ID $33.4 \mathrm{~mm}$ )

These values were agreed on by the British Standards Institution to control friction, wearing of the pipe inner walls and sedimentation. $0.7 \mathrm{~m} / \mathrm{s}$ is regarded as the self-cleaning velocity for sewage waste water (British Standards Institution, BS EN12050-1, 2015). A flow velocity of $2 \mathrm{~m} / \mathrm{s}$ was selected which was within the standard range. In order to control friction losses and allow for flow of solids suspended in the waste water, pipe sizes of $80 \mathrm{~mm}$ and above are usually selected. However, due to the small size of the prototype design, a pipe size of ID $=33.4 \mathrm{~mm}\left(1 \frac{1 / 4}{\mathrm{in}} \mathrm{pipe}\right)$ was selected.

\subsection{Design Equations}

Sewage sludge is classified as a non-Newtonian fluid. This means the relationship between the shear stress and shear rate is not linear. There are various mathematical models used for describing the relationship between shear stress and shear rate of non-Newtonian fluids. These include the power law (Oswald), Bingham plastic model, Herschel-Buckley model, Casson equation, Sisko, Carreau model and Cross model [6]. The Herschel-Buckley model was found to be proper for describing the viscosity of activated sludge at high concentration [7]. The results for Herschel-Buckley model for rheological properties of $4.96 \%$ TS and waste water sludge from Walmsley et al (2014) were used in the design calculation with $(\mathrm{m}=2.4, \mathrm{n}=0.39)$.

The Herschel-Buckley fluid combines the characteristics of a Power Law and Bingham Plastic relationship. It has the following relationship:

$\tau(\gamma)=\tau_{y}+m \gamma^{n}$

$\tau_{\mathrm{y}}=$ yield stress $(\mathrm{Pa})$

$\tau=$ shear stress $(\mathrm{Pa})$

$\mathrm{m}=$ power law consistency coefficient $\left(\mathrm{Pa} . \mathrm{s}^{\mathrm{n}}\right)$

$\mathrm{n}=$ power law flow behaviour index $(-)$

$\gamma=$ shear rate $\left(\mathrm{S}^{-1}\right)$

$\mathrm{m}=2.4$

$\mathrm{n}=0.39$

The flow condition whether laminar or turbulent for the selected flow velocity was evaluated and the Darcy friction factor was calculated. The generalized Reynolds number [8], was used for the Reynolds number of the non-Newtonian fluid, according to Equation (2), which was used to determine the friction factor used for the friction or head losses. The appropriate equations and calculations are as follows.

Generalized Reynold's Number

$$
R e_{M R}=\frac{\rho V^{2-n^{\prime}} D^{n^{\prime}}}{8^{n^{\prime}-1} m^{\prime}}
$$

$n^{\prime}=$ apparent power law index

$m^{\prime}=$ apparent consistyency coefficient

$n^{\prime}=\mathrm{n}$

$n^{\prime}=0.39$

$$
m^{\prime}=m\left(\frac{3 n+1}{4 n}\right)^{n}
$$

$\mathrm{Re}_{\mathrm{MR}}=$ generalized Reynolds number

$$
\begin{gathered}
m^{\prime}=2.4\left(\frac{3(0.39)+1}{4(0.39)}\right)^{0.39}=2.73 \\
m^{\prime}=2.73
\end{gathered}
$$

$\rho=$ density of the fluid $\left(1100 \mathrm{~kg} / \mathrm{m}^{3}\right)$

$\mathrm{v}=$ flow velocity $(2 \mathrm{~m} / \mathrm{s})$ 
$\mathrm{D}=$ flow diameter $(0.0334 \mathrm{~m})$

$$
\begin{aligned}
& R e_{M R}=\frac{1100 \times 2^{2-0.39} \times 0.0334^{0.39}}{8^{0.39-1} \times 2.73} \\
& R e_{M R}=1161.54
\end{aligned}
$$

The flow will be laminar since $\mathrm{Re}_{\mathrm{MR}}<2300$ and the Darcy friction factor, $f$ Darcy Friction Factors

$$
f=\frac{64}{R e_{M R}}=\frac{64}{1161.34}=0.055
$$

If a higher flow velocity of $3 \mathrm{~m} / \mathrm{s}$ is selected then,

$$
R e_{M R}=\frac{1100 \times 3^{2-0.39} \times 0.0334^{0.39}}{8^{0.39-1} \times 2.73} \operatorname{Re}_{M R}=2231
$$

The flow remains laminar since $\operatorname{Re}_{\mathrm{MR}}<2300$, hence a velocity of $3 \mathrm{~m} / \mathrm{s}$ could still be used. The Darcy friction factor in the case of $3 \mathrm{~m} / \mathrm{s}$ is 0.0287 , which will make the friction head loss lower than that at a flow of $2 \mathrm{~m} / \mathrm{s}$. However, $2 \mathrm{~m} / \mathrm{s}$ was used for this analysis because of the doubling effect of the velocity function.

\subsection{Major and Minor Friction Losses}

The major and minor friction losses in the piping of the system for the flow condition was now calculated. The major losses are the losses due to the pipe line while the minor losses are due to fittings such as valves, elbows and reducers [9].

The major head loss in the suction line from $\mathrm{P}_{1}$ to $\mathrm{P}_{2}$ in Figure 2 , using flow velocity $\mathrm{v}=2 \mathrm{~m} / \mathrm{s}$, pipe diameter $\mathrm{D}=0.0334 \mathrm{~m}$ and Darcy friction factor $\mathrm{f}=0.055$. The major friction loss in the pipe is given by Equation (4);

$$
\mathrm{h}_{\mathrm{l}}=\frac{\mathrm{fLV}}{2 \mathrm{D}}
$$

Taking the suction line pipe length $\mathrm{L}=5 \mathrm{~m}$ as estimated distance from inside the pit to the vacuum container, we have

$$
\mathrm{h}_{\mathrm{l}}=\frac{0.055 \times 5 \times 2^{2}}{2 \times 0.0334}=16.467 \mathrm{~J} / \mathrm{kg}
$$

The minor friction head losses in the line from P1 to P2 were estimated using Equation (5) assuming the line has a check valve and an elbow.

$$
\mathrm{h}_{\mathrm{lm}}=\frac{\mathrm{fL}_{\mathrm{e}} \mathrm{V}^{2}}{2 \mathrm{D}}
$$

Le $=$ equivalent length of fittings gotten from charts and tables published by manufacturers (Flow of fluids through valves, fittings and pipes, 1982).

$$
\begin{gathered}
\frac{\mathrm{L}_{\mathrm{e}}}{\mathrm{D}} \text { for check valve angle lift }=55 \\
\qquad \frac{\mathrm{L}_{\mathrm{e}}}{\mathrm{D}} \text { for standard elbow } 90^{\circ} \times 2 \text { nos }=30 \times 2=60 \\
\mathrm{Ke}=\text { friction loss coefficient for pipe entrance }=\left[\mathrm{h}_{\mathrm{lm}}=\frac{\mathrm{KeV}^{2}}{2}\right]=0.78 \\
\mathrm{~h}_{\mathrm{lm}}=\text { head loss check valve }+ \text { head loss elbows }+ \text { head loss pipe entrance } \\
\mathrm{h}_{\mathrm{lm}}=\frac{\mathrm{fL}_{\mathrm{e}} \mathrm{V}^{2}}{2 \mathrm{D}}+\frac{\mathrm{fL}_{\mathrm{e}} \mathrm{V}^{2}}{2 \mathrm{D}}+\frac{\mathrm{K}_{\mathrm{e}} \mathrm{V}^{2}}{2}=\frac{\mathrm{V}^{2}}{2}\left[\mathrm{f}\left(\frac{\mathrm{L}_{\mathrm{e}}}{\mathrm{D}}+\frac{\mathrm{L}_{\mathrm{e}}}{\mathrm{D}}\right)+\mathrm{K}_{\mathrm{e}}\right]
\end{gathered}
$$

Equation (6) adds up the minor head losses in the suction line.

$$
\mathrm{h}_{\mathrm{lm}}=\frac{2^{2}}{2}[0.055(55+60)+0.78]=14.21 \mathrm{~J} / \mathrm{kg}
$$

Total Head loss $h_{\mathrm{T}}=$ Major head loss $\left(\mathrm{h}_{\mathrm{l}}\right)+$ Minor head loss $\left(\mathrm{h}_{\mathrm{lm}}\right)$

$$
\mathrm{h}_{\mathrm{T}}=16.467+14.21=30.677 \mathrm{~J} / \mathrm{kg}
$$




\subsection{Vacuum Pressure in Sludge Tank}

The energy equation or Bernoulli's Equation (Equation (7)) was applied to calculate the pressure $\mathrm{P} 2$ required in the sludge tank for the sludge to be sucked up into the tank. The conditions in the sludge pit are characterized with the subscripts 1 while sludge tank with subscript 2 . Therefore, we have:

$\left(\frac{P_{1}}{\rho}+\frac{V_{1}^{2}}{2}+g h_{1}\right)-\left(\frac{P_{2}}{\rho}+\frac{V_{2}^{2}}{2}+g h_{2}\right)=h_{T}$

$\mathrm{P}_{1}=$ pressure in the sludge pit $(1 \mathrm{~atm}=101325 \mathrm{~Pa})$. Since the pit is open, the pressure in the pit is atmospheric

$\mathrm{V}_{1}=$ flow velocity in pit (the fluid is at rest in the pit $\mathrm{V}_{1}=0$ )

$\mathrm{g}=$ acceleration due to gravity $\left(9.81 \mathrm{~m} / \mathrm{s}^{2}\right)$

$\mathrm{h}_{1}=$ elevation head at point 1 (the pit is taken as $2.5 \mathrm{~m}$ deep below the datum hence it is given a negative sign)

$\mathrm{p}_{2}=$ Pressure in the sludge tank

$\mathrm{V}_{2}=$ flow velocity at the sludge tank $\left(\mathrm{V}_{2}=2 \mathrm{~m} / \mathrm{s}\right.$ the design flow velocity for the system $)$

$\mathrm{h}_{2}=$ elevation head at point $2\left(\mathrm{~h}_{2}=0\right.$ since it is taken as the datum)

$\rho=$ density of the fluid $\left(1100 \mathrm{~kg} / \mathrm{m}^{3}\right)$

Making $\mathrm{p}_{2}$ the subject of the formula, we have:

$\mathrm{P}_{2}=\rho\left[\frac{\mathrm{P}_{1}}{\rho}-\frac{\mathrm{V}_{2}{ }^{2}}{2}+\mathrm{g}\left(\mathrm{h}_{1}-\mathrm{h}_{2}\right)-\mathrm{h}_{\mathrm{T}}\right]$

From equation (8)

\section{(a) Flow Rate}

$$
\begin{gathered}
P_{2}=1100\left[\frac{101325}{1100}-\frac{2^{2}}{2}+9.807((-2.5)-0)-30.677\right] \\
P_{2}=37,302.80 \mathrm{~Pa}
\end{gathered}
$$

The flow rate into the sludge tank can be calculated using the flow velocity and area of the pipe bore using Equation (9);

$\mathrm{Q}=\mathrm{VA}$

$\mathrm{V}=$ flow velocity $(2 \mathrm{~m} / \mathrm{s})$

$\mathrm{D}=0.0334 \mathrm{~m}$

$$
A=\pi \frac{D^{2}}{4}(\text { Area of pipe bore })
$$

$$
\mathrm{Q}=\frac{2 \times \pi \times 0.0334^{2}}{4}=0.00175 \frac{\mathrm{m}^{3}}{\mathrm{~s}}\left(6.309 \frac{\mathrm{m}^{3}}{\mathrm{~h}}\right)
$$

\section{(b) Fill Time}

At this level of flow rate, the time to fill the $1001\left(0.1 \mathrm{~m}^{3}\right)$ sludge tank is:

$\mathrm{t}=\frac{\mathrm{V}}{\mathrm{Q}}=\frac{0.1}{0.00175}=57 \mathrm{~s}$

Where $\mathrm{V}=$ volume of sludge tank and $\mathrm{Q}=$ sludge volume flow rate

\subsection{Blow Pressure}

The Blow Pressure is the discharge pressure required to pump out the sludge tank. The discharge line has two elbows and a check valve. The major head loss in the discharge line from P3 to P4 in Figure 2 is calculated, using flow velocity $v=2 \mathrm{~m} / \mathrm{s}$, pipe diameter $\mathrm{D}=0.0334 \mathrm{~m}$, length of pipe, $\mathrm{L}=10 \mathrm{~m}$ and Darcy friction factor $\mathrm{f}=0.055$. The major friction loss in the pipe is given by Equation (4) as before;

$\mathrm{h}_{\mathrm{l}}=\frac{\mathrm{fLV}}{2 \mathrm{D}}$ 
Taking the discharge line pipe length $\mathrm{L}=10 \mathrm{~m}$

$$
\mathrm{h}_{\mathrm{l}}=\frac{0.055 \times 10 \times 2^{2}}{2 \times 0.0334}=32.934 \mathrm{~J} / \mathrm{kg}
$$

Estimate the minor friction head losses in the line from $\mathrm{P}_{3}$ to $\mathrm{P}_{4}$ using Equation (5) assuming the line has a check valve and two elbows, as before;

$\mathrm{h}_{\operatorname{lm}}=\frac{\mathrm{fL}_{\mathrm{e}} \mathrm{V}^{2}}{2 \mathrm{D}}$

Le $=$ equivalent length of fittings gotten from charts and tables published by manufacturers (Flow of fluids through valves, fittings and pipe, 1982).

$$
\begin{gathered}
\frac{\mathrm{L}_{\mathrm{e}}}{\mathrm{D}} \text { for check valve angle lift }=55 \\
\frac{\mathrm{L}_{\mathrm{e}}}{\mathrm{D}} \text { for standard elbow } 90^{\circ} \times 2 \text { nos }=30 \times 2=60 \\
\mathrm{Ke}=\text { friction loss coefficient for pipe entrance }=0.78\left[\mathrm{~h}_{\mathrm{lm}}=\frac{\mathrm{KeV}^{2}}{2}\right] \\
\mathrm{h}_{\mathrm{lm}}=\frac{\mathrm{head} \text { loss check valve }+ \text { head loss elbows }+ \text { head loss pipe entrance }}{2 \mathrm{D}}+\frac{\mathrm{fL}_{\mathrm{e}} \mathrm{V}^{2}}{2 \mathrm{D}}+\frac{\mathrm{K}_{\mathrm{e}} \mathrm{V}^{2}}{2}=\frac{\mathrm{V}^{2}}{2}\left[\mathrm{f}\left(\frac{\mathrm{L}_{\mathrm{e}}}{\mathrm{D}}+\frac{\mathrm{L}_{\mathrm{e}}}{\mathrm{D}}\right)+\mathrm{K}_{\mathrm{e}}\right] \quad \text { (6 repeated) }
\end{gathered}
$$

Equation 6 adds up the minor head losses in the discharge line.

$$
\begin{gathered}
\mathrm{h}_{\mathrm{lm}}=\frac{2^{2}}{2}[0.055(55+60)+0.78]=14.21 \mathrm{~J} / \mathrm{kg} \\
\text { Total Head loss } \mathrm{h}_{\mathrm{T}}=\text { Major head loss }\left(\mathrm{h}_{\mathrm{l}}\right)+\text { Minor head loss }\left(\mathrm{h}_{\mathrm{lm}}\right) \\
\mathrm{h}_{\mathrm{T}}=32.934+14.21=47.144 \mathrm{~J} / \mathrm{kg}
\end{gathered}
$$

To determine the pressure required to pump out the Vacuum Sludge Tank, we applied the energy equation (equation (10)) to calculate the pressure P3 required to empty the sludge tank.

$\left(\frac{\mathrm{P}_{3}}{\rho}+\frac{\mathrm{V}_{3}^{2}}{2}+\mathrm{gh}_{3}\right)-\left(\frac{\mathrm{P}_{4}}{\rho}+\frac{\mathrm{V}_{4}^{2}}{2}+\mathrm{gh}_{4}\right)=\mathrm{h}_{\mathrm{T}}$

$\mathrm{P}_{4}=$ pressure in the disposal tank $(1 \mathrm{~atm}=101325 \mathrm{~Pa})$. Since the tank is open, the pressure in the disposal tank is atmospheric

$\mathrm{V}_{4}=$ flow velocity at the point of entry into disposal tank $\left(\mathrm{V}_{2}=2 \mathrm{~m} / \mathrm{s}\right.$ the design flow velocity for the system)

$\mathrm{g}=$ acceleration due to gravity $\left(9.807 \mathrm{~m} / \mathrm{s}^{2}\right)$

$\mathrm{h}_{4}=$ elevation head at point 4 (the pit is taken as $3 \mathrm{~m}$ high above the datum hence it is given a positive sign)

$\mathrm{P}_{3}=$ Pressure in the sludge tank for discharge phase

$\mathrm{V}_{3}=$ flow velocity in sludge tank (the fluid is at rest in the tank $\mathrm{V}_{3}=0$ )

$\mathrm{h}_{3}=$ elevation head at point $3\left(\mathrm{~h}_{3}=0\right.$ since it is taken as the datum)

$\rho=$ density of the fluid $\left(1100 \mathrm{~kg} / \mathrm{m}^{3}\right)$

Make $\mathrm{p}_{3}$ the subject of the formula of Equation (10)

$\mathrm{P}_{3}=\rho\left[\frac{\mathrm{P}_{4}}{\rho}+\frac{\mathrm{V}_{4}{ }^{2}}{2}+\mathrm{g}\left(\mathrm{h}_{4}-\mathrm{h}_{3}\right)+\mathrm{h}_{\mathrm{T}}\right]$

From equation (11)

$$
\begin{gathered}
P_{3}=1100\left[\frac{101325}{1100}+\frac{2^{2}}{2}+9.81(3-0)+47.144\right] \\
P_{3}=187,756 \mathrm{~Pa}
\end{gathered}
$$

Hence, from the design values, it was ascertained that for suction from the pit $2.5 \mathrm{~m}$ deep and at a distance of 5 meters to the sludge vacuum tank to occur a pressure of $54832.95 \mathrm{~Pa}$ (vacuum) in the 
tank is required. Similarly, to discharge the sludge from the sludge tank through a distance $10 \mathrm{~m}$ and height 3 meters, a pressure of 187,756 Pa would be required.

\subsection{Pressure in the Water Ring Vacuum Pump}

Here, we considered the evacuation of gas from the sludge chamber. The vacuum system is created by drawing the air in the sludge chamber through the water-ring pump and then discharging to atmosphere. The determination of the pressure regime for the evacuation of the sludge chamber through the vacuum pump followed the principle of gas flow. The setup is illustrated in Figure 3 showing the vacuum chamber connected with a short $25.4 \mathrm{~mm}$ (1") tube to the water-ring pump. For this analysis, we first characterize the gas flow condition in the vacuum system. Two criteria were examined: the Knudsen number, Kn, and the Reynold's number, Re.

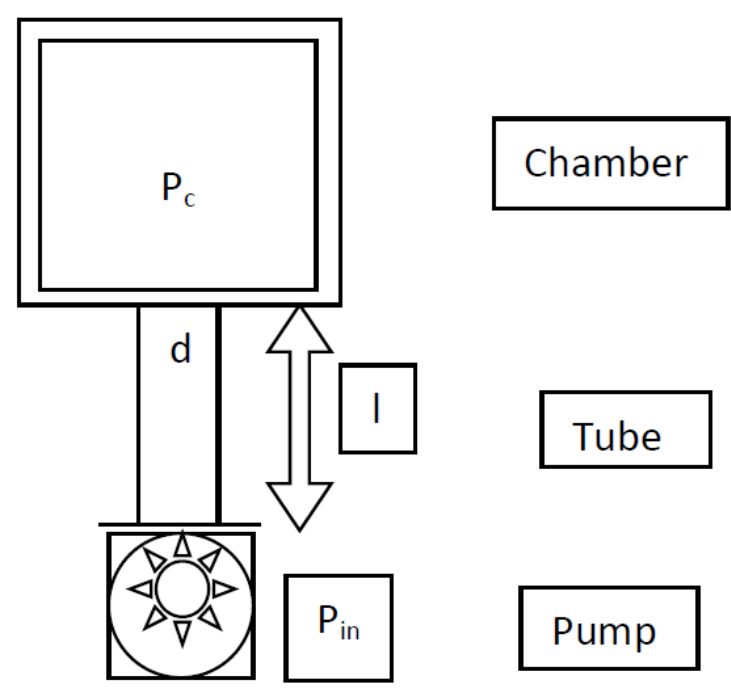

Figure 3: Evacuating a vacuum chamber through a tube

The Knudsen number is the ratio of the mean free path $\bar{\imath}$ of the gas particles between two particleparticle collision and the characteristic geometrical dimension $d$ of the tube's cross section (for circular tube cross sections, the diameter). The flow in the system can be determined whether molecular, transitional or viscous, (i.e. continuum) based on the Knudsen number [10]. The diagram, Figure 4 defines the limits of characteristic behaviour of gas depending on the vacuum pressure. As the vacuum pressure gets higher (lower pressure), the gas molecules in a given space becomes fewer and fewer and hence the mean free path gets larger and no longer flow as a continuum.

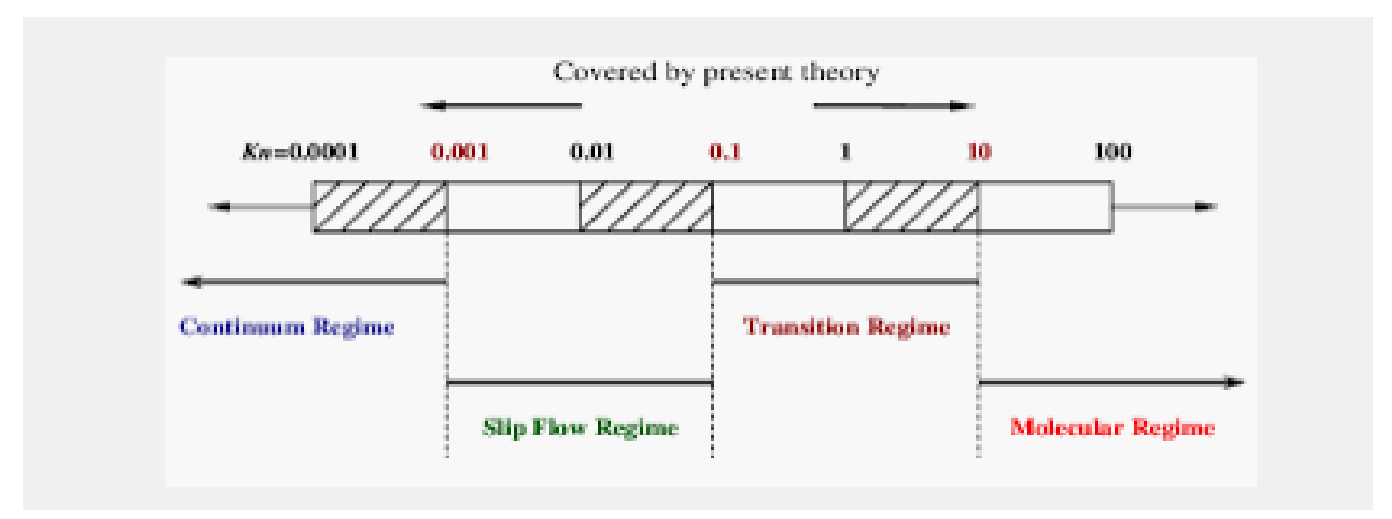

Figure 4: Classification of Air Flow by Knudsen Number 
We used the three-level definition of the Knudsen numbers, from the highest vacuum to the lowest vacuum, as given below.

$\mathrm{K}_{\mathrm{n}}>0.5$ molecular flow

$0.5>\mathrm{K}_{\mathrm{n}}>0.01$, transitional flow

$\mathrm{K}_{\mathrm{n}}<0.01$ viscous flow

The Knudsen number increases as the vacuum pressure increases, i.e. decreases below atmosphere.

The formulae for the Knudsen number are given as:

$\mathrm{K}_{\mathrm{n}}=\frac{\overline{\mathrm{l}}}{\mathrm{d}}$

$\mathrm{K}_{\mathrm{n}}=\frac{\pi}{4} \times \frac{\overline{\mathrm{c}} \eta}{\mathrm{pd}}$

$$
\begin{aligned}
& \eta=\text { viscosity of air } 18.2 \times 10^{-6} \mathrm{PaS} \text { at } 20^{\circ} \mathrm{C} \\
& \overline{\mathrm{c}}=\text { mean thermal speed } 463 \mathrm{~m} / \mathrm{s} \\
& \overline{\mathrm{l}}=\text { mean free path } \\
& \mathrm{p}=\text { pressure of the gas in the chamber } 37302.8 \mathrm{~Pa} \\
& \mathrm{~d}=\text { dimension of the tube' } \text { cross section (hydraulic diameter) } 0.0254 \mathrm{~m}
\end{aligned}
$$

From equation (13)

$$
\mathrm{K}_{\mathrm{n}}=\frac{\pi}{4} \times \frac{18.2 \times 10^{-6} \times 463}{37302.8 \times 0.0254}=6.7634 \times 10^{-6}=0.00000889
$$

From the Knudsen number the flow in the $25.4 \mathrm{~mm}$ ( $1 \mathrm{inch}$ )-pipe is viscous or continuum.

The second criteria needed to characterize the gas flow is the Reynolds number Re which tells us if the flow is laminar or turbulent. The formula for Reynolds number is given in Equation (14)

$\operatorname{Re}=\frac{\rho v d}{\eta}$

$$
\begin{gathered}
\text { Re }<2300, \text { laminar flow, } \\
\operatorname{Re}>4000, \text { turbulent flow. } \\
\eta=\text { viscosity of air } 18.2 \times 10^{-6} \mathrm{PaS} \text { at } 20^{\circ} \mathrm{C} \\
\rho=\text { density of air at } 20^{\circ} \mathrm{C} \\
\mathrm{v}=\text { average velocity in duct } \\
\mathrm{d}=\text { diameter of the tube } 0.0254 \mathrm{~m}
\end{gathered}
$$

The density of air is given by equation (15)

$\rho=\frac{\mathrm{m}}{\mathrm{V}}=\frac{\mathrm{pM}}{\mathrm{RT}}$

$$
\begin{gathered}
\mathrm{p}=101325 \mathrm{~Pa} \\
\mathrm{M}=\text { mean molar mass of air }=28.964 \times 10^{-3} \mathrm{~kg} \mathrm{~mol}^{-1} \\
\mathrm{R}=\text { Molar gas constant } 8.314472 \mathrm{Jmol}^{-1} \mathrm{~K}^{-1} \\
\mathrm{~T}=\text { temperature } 20^{\circ} \mathrm{C}=293.15 \mathrm{~K} \\
\rho=\frac{101325 \times 28.964 \times 10^{-3}}{8.314472 \times 293.15}=1.2041 \mathrm{kgm}^{-3}
\end{gathered}
$$

To calculate the average velocity of the air being pumped, we first estimate the effective pumping speed in the chamber. We will start by defining the following parameters:

$\mathrm{S}=$ Volume flow rate at pump inlet or pumping speed

$S_{\text {eff }}=$ Effective pumping speed or pumping speed available at chamber outlet;

$\mathrm{Q}=\mathrm{q}_{\mathrm{pv} \text { inlet }}=$ Throughput at pump inlet

$\mathrm{p}_{\mathrm{c}}=$ Sludge chamber pressure

$\mathrm{p}_{\mathrm{in}}=$ inlet pressure at pump entrance

$\mathrm{C}=$ Conductance 
The following equations will apply with consideration to the flow in the short tube connecting the chamber to the pump.

The throughput is the same at tube inlet and outlet, that is:

$\mathrm{q}_{\mathrm{pv}}=\mathrm{p}_{\mathrm{c}} \mathrm{S}_{\mathrm{eff}}=\mathrm{p}_{\mathrm{in}} \mathrm{S}$

Therefore,

$\mathrm{S}_{\mathrm{eff}}=\left(P_{\text {in }} / P_{c}\right) \mathrm{S}<\mathrm{S}$

The conductance is given as:

In the flow of gases in vacuum, there is a point where the speed is maximum and no amount of reduction of pressure will make the speed exceed this speed. This speed is equal to the speed of sound in that gas and the gas properties at this point are referred to as critical properties, that is, critical speed, $\mathrm{S}^{*}$, critical pressure, $\mathrm{p}^{*}$, critical throughput, $\mathrm{Q}^{*}$ or $P_{p v} *$, etc. At this stage, the gas flow is said to have achieved choked flow. This condition is used to determine flows in pipes because they have been determined and charted.

At this critical stage, the throughput is $q_{p v^{*}}$, we have;

$\frac{q_{p v} *(\text { nozzle })}{q_{p v}(\text { pump inlet })}=\frac{P_{c} * S *}{P_{i n} S}$

The critical volume flow rate is given as:

$S^{*}=\frac{\pi}{4} d^{2} \sqrt{\frac{\pi}{4}} \bar{c} \Psi\left(\frac{p^{*}}{P_{c}}\right)$

The parametric values for the critical state are:

Flow function at critical point, $\Psi\left(\frac{\mathrm{P}^{*}}{\mathrm{P}_{1}}\right)=0.484$ for air (considered as Nitrogen)

Mean thermal particle speed, $\bar{c}=463 \mathrm{~ms}^{-1}$

Pipe connection chamber-pump, $\mathrm{d}=25.4 \mathrm{~mm}(0.0254 \mathrm{~m})$

Substituting into Equation (21), we have:

$S^{*}=\frac{\pi}{4}(0.0254)^{2} \sqrt{\frac{\pi}{4}}(463) *(0.484)=0.0975 \mathrm{~m}^{3} \mathrm{~s}^{-1}\left(97.5 l \mathrm{~s}^{-1}\right)$

This is equivalent to a pumping speed of $0.0975 \times 60 \times 60=351 \mathrm{~m}^{3} / \mathrm{hr}$ or $351,000 \mathrm{l} / \mathrm{s}$. This is apparently a very high pumping capacity and a high-powered pump will be required to achieve choked flow. Hence, to reduce the flow, a $1 / 2$ inch $(12.5 \mathrm{~mm})$ nozzle was attached at the exit from the chamber to reduce the flow diameter to $12.5 \mathrm{~mm}$. with this reduction the critical flow rate was reduced to:

$S^{*}=\frac{\pi}{4}(0.0125)^{2} \sqrt{\frac{\pi}{4}}(463) *(0.484)=0.0244 \mathrm{~m}^{3} \mathrm{~s}^{-1}\left(24.4 l \mathrm{~s}^{-1}\right)$

As noted earlier, though the throughput through the duct is the same, the volumetric flow rates are different between the chamber and the pump inlet. The pressure at the pump inlet has to be less than the pressure at the chamber for flow to occur while the volumetric flow rate, $S$, has to be higher, in this case higher than $S^{*}$. From the Equation (20), repeated below,

$\frac{q_{p v} *(\text { nozzle })}{q_{p v}(\text { pump inlet })}=\frac{P_{c} * S *}{P_{i n} S}$

(20 repeated)

We have,

$\frac{P_{i n} q_{p v^{*}}}{P_{c} * q_{p v}}=\frac{S *}{S}$

The ratio $\frac{S *}{S}$ has a complex relationship with the ratios $\frac{P_{i n}}{P_{c^{*}}}$ and $\frac{q_{p v^{*}}}{q_{p v}}$ as can be seen and these could only be determined experimentally. The associated values are plotted in a nomograph which is used in the analysis of the pumping parameters. The nomograph is featured in the Figure (5) 
showing the ratio $\frac{P_{\text {in }}}{P_{c^{*}}}$ plotted along the ordinate and the ratio $\frac{q_{p v^{*}}}{q_{p v}}$ plotted on the abscissa. The ratio $\frac{S *}{S}$ are lines radiating from the origin. The line $\frac{S *}{S}=0.53$ is the ratio for choked flow.

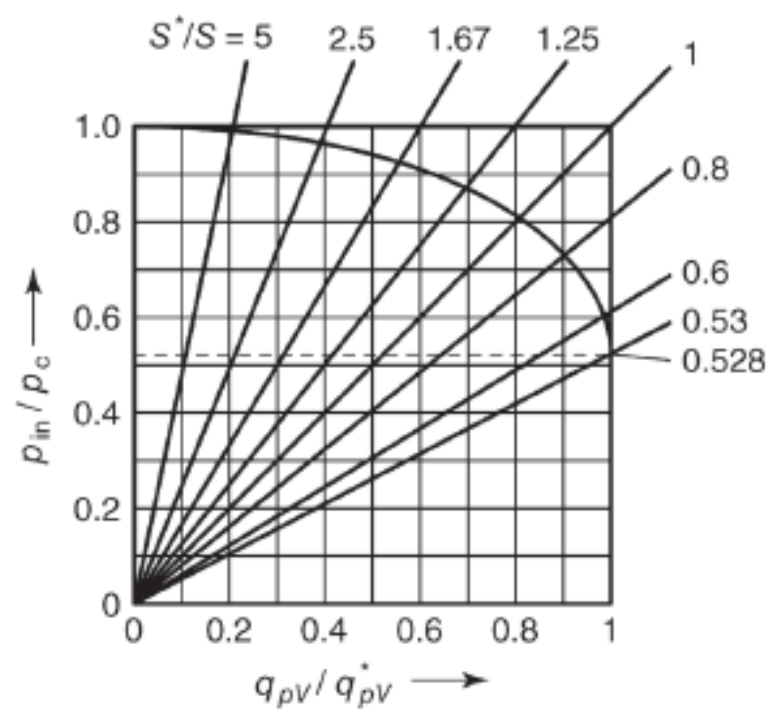

Figure 5: Nomograph for determining gas flow through nozzles for inviscid fluid

For this critical flow, $\frac{S *}{S}=0.70$ is assumed (i.e. $70 \%$ net volume, which gives $\mathrm{S}=35 \mathrm{l} / \mathrm{s}$. With the $S$ ratio, the values $\frac{P_{i n}}{P_{c} *}$ and $\frac{q_{p v^{*}}}{q_{p v}}$ are read off from the nomograph as 0.68 and 0.95 (approximate values), respectively. Given the chamber pressure as $1013 \mathrm{mbar}$ and $\frac{P_{\text {in }}}{P_{c^{*}}}$ as 0.68 , the pressure $\mathrm{p}_{\text {in }}$ will be 689 mbar for the critical flow. Investigating the throughput gives:

$1013 \times 24.4=689 \times 35$

$$
\mathrm{p}_{\mathrm{c}} \mathrm{S}^{*}=\mathrm{p}_{\mathrm{in}} \mathrm{S}
$$

$24,717 \mathrm{mbar}^{-1} \mathrm{~s}^{-1} \approx 24,115 \mathrm{mbar} l \mathrm{~s}^{-1}$

The critical flow rate is also the effective volumetric flow rate at the nozzle or orifice. The velocity decreases immediately after the nozzle as the duct widens to the $25.4 \mathrm{~mm}$ diameter used to connect to the pump.

The velocity at the nozzle is determined using Equation (6) given as:

$$
S_{\text {eff }}=v A=\frac{v \pi D^{2}}{4}
$$

Where $v=$ air velocity in duct, $\mathrm{A}=$ area of duct and $D=$ diameter of duct $=0.0125 \mathrm{~m}$

Rearranging,

$$
\begin{gathered}
v=\frac{4 S_{\text {eff }}}{\pi D^{2}} \\
S_{\text {eff }}=0.0244 \mathrm{~m}^{3} \mathrm{~s}^{-1}\left(24.4 l \mathrm{~s}^{-1}\right) \\
D=0.0125 \mathrm{~m} \\
v=\frac{4 \times 0.0244}{\pi \times 0.0125^{2}}=198.829 \mathrm{~ms}^{-1}
\end{gathered}
$$

However, the duct widens to, $\mathrm{d}=0.0254 \mathrm{~m}$ immediately after the nozzle to connect to the pump. Hence, using

Velocity at pump inlet, $v_{\text {in }}$ is

$$
S_{\text {eff }}=v A
$$

$$
\operatorname{vin}=\frac{S_{e f f}}{\pi d^{2}}
$$


Sadjere, E.G. and Iloba, N. / NIPES Journal of Science and Technology Research

$$
\operatorname{vin}=\frac{4 \times 0.0244}{\pi \times 0.0254^{2}}=48.154 \mathrm{~ms}^{-1}
$$

Now, the Reynold's number is given as,

$$
R e=\frac{\rho v d}{\eta}
$$

Where, $\rho=$ density of air, $v=$ velocity of air, $d=$ diameter of connecting pipe and $\eta=$ viscosity of air. The specifications for air are:

$$
\begin{gathered}
\rho=1.2041 \mathrm{kgm}^{-3} \\
v=48.154 \mathrm{~ms}^{-1} \\
d=0.0254 \mathrm{~m} \\
\eta=\text { viscosity of air } 18.2 \times 10^{-6} \text { Pas at } 20^{\circ} \mathrm{C}
\end{gathered}
$$

Therefore,

$$
R e=\frac{\rho v D}{\eta}=\frac{1.2041 \times 48.154 \times 0.0254}{18.2 \times 10^{-6}}=80920
$$

The air flow is turbulent since $\operatorname{Re}>4000$

The flow rate $S^{*}$ is the critical flow rate, which means that even when the pressure at the pump inlet is increased, the speed at the nozzle will not increase as it is the speed of sound in the given gas (air). However, for the pressure at the chamber to be reduced to $37302 \mathrm{~Pa}$ (373 mbar), the pressure at the pump inlet must be reduced to $37302 \mathrm{~Pa}$ as well. At this pressure, $37302 \mathrm{~Pa}$ at the pump inlet, flow seizes.

\section{Results and Discussion}

The analysis produced the following results of the pressures required to move materials around the system. A vacuum pressure, $\mathrm{P}_{2}$ of $37,302 \mathrm{~Pa}$ is required in the sludge tank for the suction of slurry and overcome friction in the suction line. This will produce a flow rate of $0.00175 \mathrm{~m}^{3} / \mathrm{s}$ at a velocity of $2 \mathrm{~m} / \mathrm{s}$ and filling the $0.1 \mathrm{~m} 3$ sludge tank in $57 \mathrm{~s}$. The blow pressure to evacuate the slurry from the sludge tank, on the other hand, is $187,576 \mathrm{~Pa}$. The water-ring vacuum pump required pumping speed of $0.0975 \mathrm{~m}^{3} / \mathrm{s}$ or $97.5 \mathrm{l} / \mathrm{s}$ of air. This is the critical flow rate and no further reduction of pressure can increase this flow rate. The critical flow rate is achieved at vacuum pressure of $68,900 \mathrm{~Pa}(689$ mbar). However, in other to achieve the sludge tank pressure of 37,302 Pa, the pump pressure must be reduced to this pressure after which flow will seize

\section{Conclusion}

The process of calculating pressure in a water-ring pump suction system was established. The slurry to be pumped was considered a non-Newtonian fluid, hence non-Newtonian fluid flow equation, the Herschel-Buckley equation was used to calculate the friction loss in the hose before the Bernoulli's energy equation was used to calculate the suction and blow pressures. The initial pressure in the sludge tank was atmospheric, 101,325 $\mathrm{Pa}$ while the final pressure to achieve suction of the faecal slurry was determined as $37,302 \mathrm{~Pa}$. The pressure in the pump was calculated using gas flow equations. The equations were first used to determine the type of flow using the Knudsen number and Reynold's number. With a Knudsen number of 0.00000889 and Reynold's number 80920, the air flow is continuous but turbulent. The critical pressure of $68,900 \mathrm{~Pa}$ is required for the critical volumetric flow rate, which cannot be exceeded even when the pressure in the pump is taken below the critical pressure. 


\section{References}

[1] Sridhar, MKC, Wahab, B, Oloruntoba, EO, and Idachaba, A (2011). Landscape Analysis and Business model Assessment of Fecal Sludge Management: Extraction and Transportation Models in Africa - Nigeria Study Report. www.susana.org>default.2-1671-nigeria-fsm..

[2] Ezekwe, I.C., Odubo, T.V., Odubo, E. and Akosa, J. (2011). Housing, Sanitation and Faecal Sludge Management in Owerri, Nigeria. Journal of Geographic Thought (Journal of Geography and Environmental Management). University of Port Harcourt 12(1 \& 2) $89-102 \mathrm{~s}$

[3] O'Riordan, M., (2009). Investigation into methods of pit latrine emptying. Partners in Development WRC Project, 1745.

[4] Muller, M. and Rijnsburger, J., (1994). MAPET: An appropriate latrine-emptying technology. Waterlines, 13(1), pp.24-27.

[5] UN-HABITAT (1995). The Vacutug Design and Trial. UN-HABTAT for a Better Urban Future. mirror.unhabitat.org/categories.asp?catid $=548$

[6] Garakani, A.K., Mostoufi, N., Sadeghi, F., Fatourechi, H., Sarrafzadeh, M. and Mehrnia, M., (2011). Comparison between different models for rheological characterization of activated sludge. Journal of Environmental Health Science \& Engineering, 8(3), pp.255-264.

[7] Guibaud, G., Dollet, P., Tixier, N., Dagot, C. and Baudu, M., (2004), July. Characterisation of the evolution of activated sludges using rheological measurements. Process Biochemistry; 39(11):1803-10.

[8] Chhabra, R.P., and Richardson, J.F., (1999). Non-Newtonian flow in the process industries: fundamentals and engineering applications. Butterworth-Heinemann.

[9] Fox, R., McDonald, A., Pritchard, P., Leylegian J.C., (2011). Fluid Mechanics. 8th. 1.

[10] Jousten K., editor. (2016), August, 22. Handbook of vacuum technology. John Wiley \& Sons. 